\title{
AUTOMATIC IDENTIFICATION OF RING ENHANCING LESION PATTERN IN CASES OF BRAIN INFECTION AND METASTASIS BRAIN TUMOR BASED ON INVARIANT MOMENT FEATURES CLASSIFICATION
}

\author{
Riries Rulaningtyas $^{1 a^{*}}$, Lailatul Muqmiroh ${ }^{2 b}$, Leonard Ferdian ${ }^{1 c}$, Abidah Alfi $^{1 \mathrm{~d}}$, Isma Iba ${ }^{1 \mathrm{e}}$ \\ ${ }^{1}$ Biomedical Engineering Study Program, Department of Physics, Faculty of Science and Technology, Universitas \\ Airlangga, Jalan Mulyorejo, Surabaya, 60115, INDONESIA. E-mail: riries-r@ fst.unair.ac.id ${ }^{a}$; \\ lailatul.muqmiroh@vokasi.unair.ac.id ${ }^{\text {b; }}$ leo@dataku.web.id ${ }^{c}$; rigeliastar@gmail.com ${ }^{\text {d; }}$ ismaiba97@gmail.com ${ }^{\mathrm{e}}$ \\ ${ }^{2}$ Radiologic Technology Program, Faculty of Vocational Studies, Airlangga University, Jalan Dharmawangsa Dalam \\ 25-30, Surabaya, 60286, INDONESIA, E-mail: liling.sahadi@gmail.com ${ }^{\text {b }}$ \\ *Corresponding Author: riries-r@fst.unair.ac.id \\ Submitted: 31 $1^{\text {st }}$ December $2018 \quad$ Accepted: $15^{\text {th }}$ October 2019 \\ Published: $30^{\text {th }}$ November 2019
}

DOI: https://doi.org/10.22452/mjs.sp2019no3.5

\begin{abstract}
Brain infection and metastasis brain tumor in CT Scan examination have similar ring-enhancing lesion patterns. This research aims to develop a program that aids the radiologists to identify these brain disorders. The radiologists often have difficulties and mostly subjective when distinguishing the ring-enhancing lesion whether brain infection or metastatic brain tumor, especially in patients with no previous history of the disease. With these limitations, this research produces a Computer Aided Diagnose (CAD) system in order to assist the radiologists in brain disorders observing from the images of CT scan brain scanning. The CAD system is supported by features extraction method which is generated using the combinations of Hu's invariant moment features. The decision maker uses the backpropagation neural network method to classify the brain disorders based on their invariant moment features that could help the radiologists when identifying the brain abnormalities. The results of brain abnormalities identification including normal, brain infection, and metastasis brain tumor yielded performance with $88.9 \%$ accuracy, $86 \%$ sensitivity, and $100 \%$ specificity.
\end{abstract}

Keywords: CT scan, identification, invariant moment features, backpropagation, neural network.

\section{INTRODUCTION}

Brain infection and metastasis brain tumor are serious diseases with high number of cases. Radiology imaging is an important part for brain abnormalities diagnosis. The most frequently used radiology instruments for the diagnosis of brain tumor and metastasis brain tumor are CT Scan and Magnetic Resonance Imaging (MRI). MRI has an ability to distinguish brain infection and metastasis brain tumor more accurately and appears to be clearer shape than CT Scan in those two brain abnormalities with similar shapes with multiple ring enhancing. The most imaging modality that used in the hospital is CT Scan because the CT Scan has lower cost than MRI. Lesions that describes the infection process or metastases in the brain on CT scan seen as a ring enhancing lesion after given contrast. The radiologists often have difficulty to distinguish ring enhancing lesion from CT Scan images, an infection process, or metastases especially 
on patients with unknown illness history before. With those limitations, a type of research is needed to diagnose $\mathrm{CT}$ scan image with image processing method so that the radiologist can distinguish various kind of brain abnormalities such as infection and metastatic tumors in brain.

In this research, we use appropriate pattern recognition methods to distinguish the object of ring lesions in brain resulted from CT Scan scanning with two kinds of classification whether brain infection or metastasis brain tumor. In this study, we use Hu's moment invariant that can measure the quantities of the particular differential pattern which has the discriminant power to differentiate the pattern between these two abnormalities brain diseases.

Zhang et al (2015) used Hu's moment invariant as feature extraction with classification accuracies of $100 \%$ over Dataset-66, 100\% over Dataset-160, and 99.45\% over Dataset-255. Zunic, et al (2010) used $\mathrm{Hu}$ moment invariants that could detect small irregularities in nearly circular shapes broken by noise. Moment invariant is proven to have high ability to trace the pattern of images with images translation, scaling, rotation, and free from noise (Huang \& Leng, 2010), hence this research uses the Hu's moment invariant as feature extraction and backpropagation neural network as the classification method. But before that, an image processing method is conducted which consists of preprocessing and segmentation. Feature extraction for this research used 7 combination of $\mathrm{Hu}$ 's moment invariant method and the backpropagation neural network method classifies the characteristics from a unique object to represent the shape to distinguish the two of brain abnormalities cases with feature extraction of a ring enhancing shape on infection and metastatic. All data that will be processed in this research is a data result of CT Scan modality test. Generated data will be in the form of images with various kind of gray intensity that describes brain structure along with abnormalities (lesions) for brain infection and metastatic cases.

\section{THE RING ENHANCEMENT LESION PATTERN}

The ring enhancing pattern is a difficult pattern to be analyzed in neuroimaging, especially in the metastasis brain tumor and brain infection images that resulted from CT Scan. The lesion pattern of both brain abnormalities are similar each other that form the ring enhancement pattern. This ambiguity pattern can cause the decreasing accuracy of the radiologist diagnosis, even less the patients do not have the exact previous symptoms.

The pattern of ring lesion in the brain infection has the ring with smooth line, but in the metastasis brain tumor has rough and irregular line shapes. The Figure 1(a) represents the ring lesion pattern of brain infection and (b) malignant brain tumor. The radiologists have difficulties to distinguish both these patterns visually from CT Scan images. In some cases, these brain abnormalities show the multiple ring enhancing lesions as shown in Figure 2. 


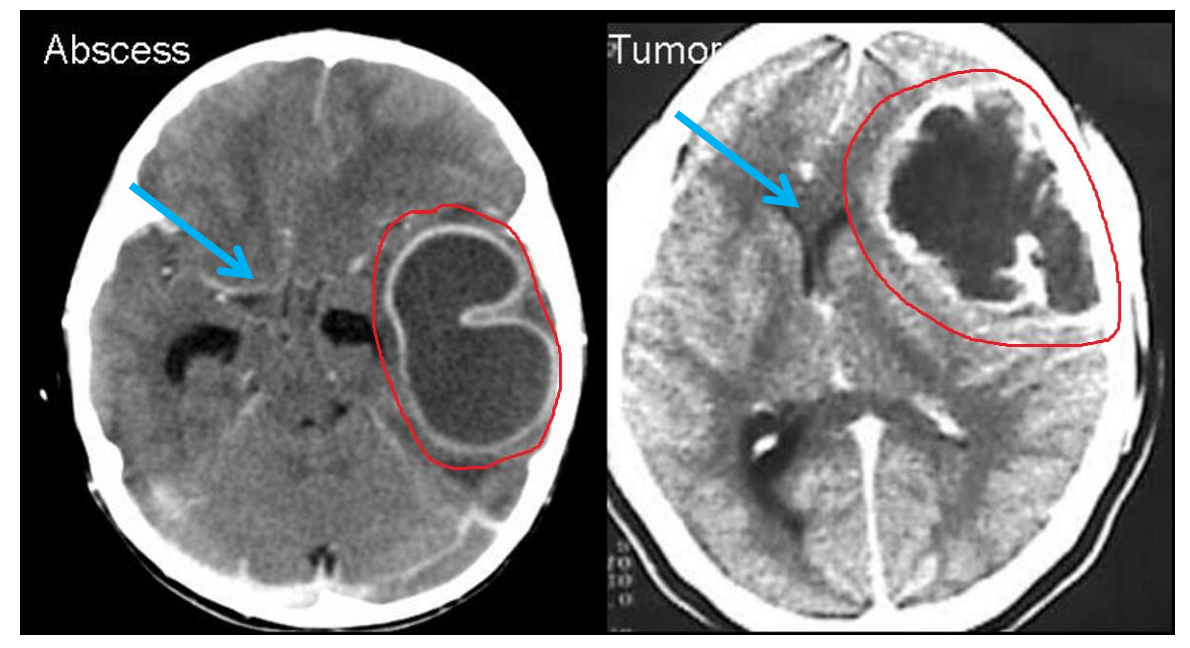

(a)

(b)

Figure 1. The Ring Enhancing Lesion Pattern

(a) In The Brain Infection (b) In The Brain Tumor (Claussen et al, 1982)

The ring pattern in Figure 3 sometimes is similar with the pattern of Glioblastoma and metastasis.

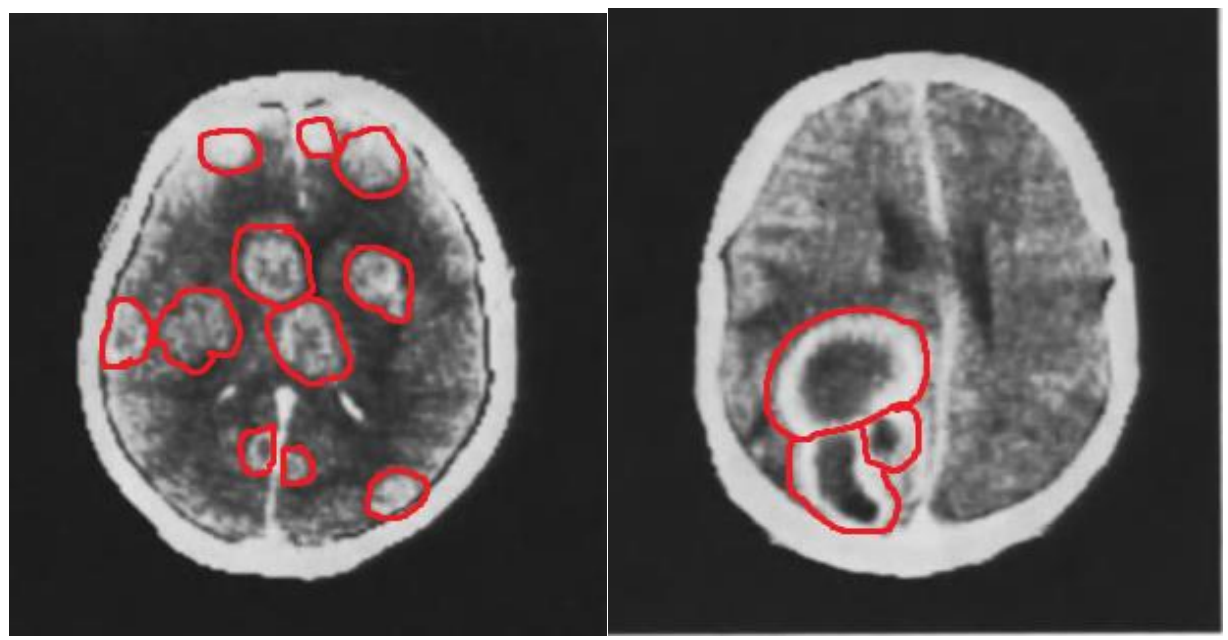

(a)

(b)

Figure 2. The Multiple Ring Enhancing Lesions in (a) The Metastasis Brain Tumor (b) The Brain Infection (Claussen et al, 1982)

3. THE HU MOMENT INVARIANTS

Moment Invariant is introduced by orthogonal invariants and an orthogonal invariant based on algebraic invariants. The 2-D moment with order $(a+b)$ in the digital image $g(m, n)$ is defined as (Zhang, 2016) :

$\mathrm{Hu}$ that formulate the six absolute

$$
\text { moment }_{a b}=\sum_{m} \sum_{n} m^{a} n^{b} g(m, n)
$$


Where :

$$
\begin{aligned}
& \text { moment }_{a b}=\text { the moment of digital images } \\
& a, b=\text { the moment order } \\
& g=\text { the value of image intensity } \\
& m, n=\text { the pixel coordinate }
\end{aligned}
$$

For $a, b=0,1,2, \ldots$, where the sum of $(a+b)$ order is above the value of $m$ and $n$ image's spatial coordinate. The central moment is defined as (Zhang, 2016)

$\varphi_{a b}=\sum_{m} \sum_{n}(m-\bar{m})^{a}(n-\bar{n})^{b} g(m, n)$

Where $\bar{m}=\frac{A_{10}}{A_{00}}$ dan $\bar{n}=\frac{A_{01}}{A_{00}}$

$A_{00}=$ area of whole images

$A_{10}=$ area of the object in the horizontal direction

$A_{01}=$ area of the object in the vertical direction

$\varphi=$ center moment

$\bar{m}, \bar{n}=$ center image

The Normalized central moment from the order $(a+b)$ is defined as :

$\psi_{a b}=\frac{\varphi_{a b}}{\varphi_{00}^{\beta}}$, for $a, b=0,1,2, \ldots$

where :

$\beta=\frac{a+b}{2}+1$, for $a+b=2,3, \ldots$

The 7 moment invariants which are not sensitive to the translation, scale change, and rotation are derived as (Zhang, 2016) :

$$
\begin{aligned}
& \Theta_{1}=\psi_{20}+\psi_{02} \\
& \Theta_{2}=\left(\psi_{20}-\psi_{02}\right)^{2}+4 \psi_{11}^{2} \\
& \Theta_{3}=\left(\psi_{30}-3 \psi_{12}\right)^{2}+\left(3 \psi_{21}-\psi_{03}\right)^{2} \\
& \Theta_{4}=\left(\psi_{30}+\psi_{12}\right)^{2}+\left(\psi_{21}-\psi_{03}\right)^{2} \\
& \Theta_{5}=\left(\psi_{30}-\psi_{12}\right)\left(\psi_{30}+\psi_{12}\right)\left[\left(\psi_{30}+\psi_{12}\right)^{2}-3\left(\psi_{21}+\psi_{03}\right)^{2}\right]+\left(3 \psi_{21}+\right. \\
& \left.\psi_{03}\right)\left(\psi_{21}+\psi_{03}\right)\left[3\left(\psi_{30}+\psi_{12}\right)^{2}-\left(\psi_{21}+\psi_{03}\right)^{2}\right] \\
& \Theta_{6}=\left(\psi_{20}-\psi_{02}\right)\left[\left(\psi_{30}+\psi_{12}\right)^{2}-\left(\psi_{21}+\psi_{03}\right)^{2}\right]+ \\
& 4 \psi_{11}\left(\psi_{30}+\psi_{12}\right)\left(\psi_{21}+\psi_{03}\right) \\
& \Theta_{7}=\left(3 \psi_{21}-\psi_{03}\right)\left(\psi_{30}+\psi_{12}\right)\left[\left(\psi_{30}+\psi_{12}\right)^{2}-3\left(\psi_{21}+\psi_{03}\right)^{2}\right]+\left(3 \psi_{21}+\right. \\
& \left.\psi_{03}\right)\left(\psi_{21}+\psi_{03}\right)\left[3\left(\psi_{30}+\psi_{12}\right)^{2}-\left(\psi_{21}+\psi_{03}\right)^{2}\right]
\end{aligned}
$$




\section{NEURAL NETWORK}

Artificial neural network is an algorithm system that has characteristics similar to human nerve tissue. Backpropagation is a supervised learning algorithm and is used by many layers of perceptrons to change the weights connected to neurons in the hidden layer. Figure 3 shows the Backpropagation network architecture.

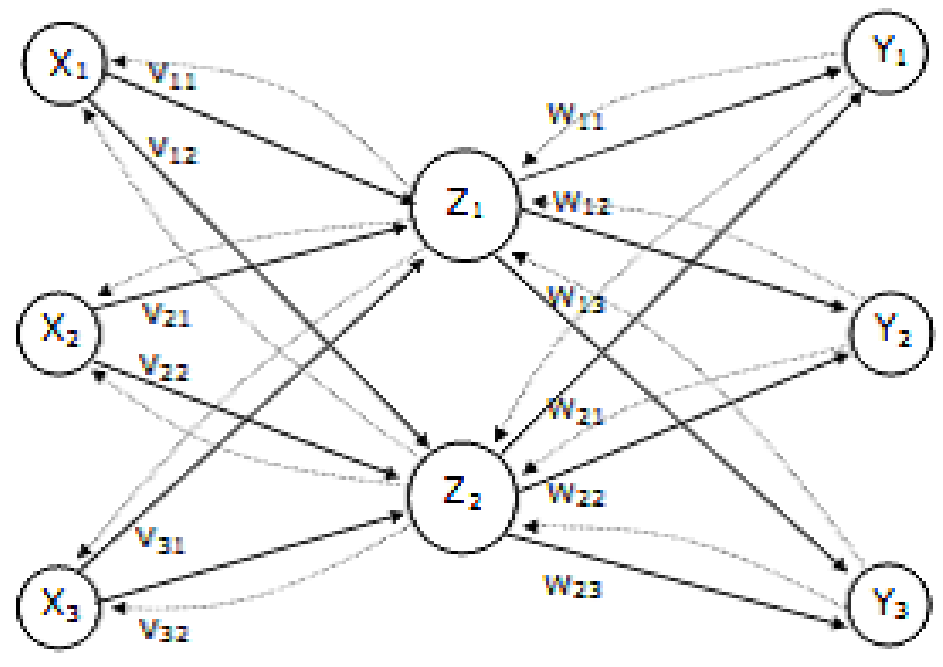

Figure 3. Backpropagation network architecture (Sun, 2016)

\section{EXPERIMENTS}

\subsection{Method}

In order to identify ring enhancing lesion in brain metastases and infection, we used images that were acquired from CT scan. Computed Tomography (CT) usually called Computed Axial Tomography (CAT), Computer-assisted Tomography, or (body section rontgenography) uses digital processing to generate an internal three dimensions image of an object from $\mathrm{x}$-rays that will generates two-dimension image. CT scan could give one tumor tissue image with another. CT scan could also give lesions density abnormalities image, and could be clarified by giving contrast (Dewi, Loho, \& Tubagus, 2015).

Variety of CT Scan data used in this research are images of brain infection, metastases, and normal condition which have been examined by radiologists. The image data used in this research is DICOM (.dcm) which was the original image acquired from CT Scan instrument. Image obtained has size of $512 \times 512$ pixels, and was taken from CT-Scan multislice instrument with maximum X-ray generator of $120 \mathrm{kV}$. 


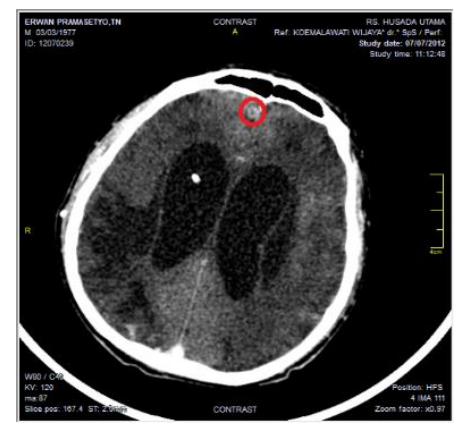

(a)

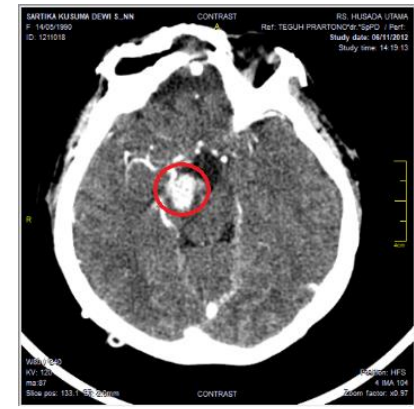

(b)

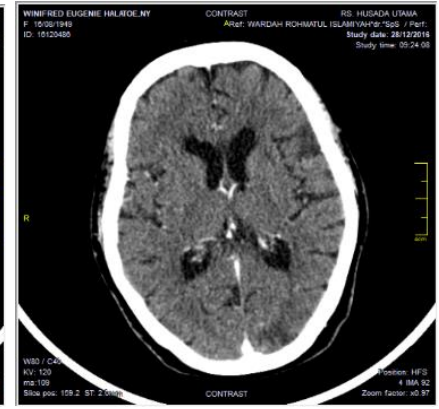

(c)

Figure 4. The Sample Data CT Scan, (a) Brain Infection (b) Metastasis Brain Tumor (c) Normal Brain

All of the data are categorized into training data and test data. $70 \%$ of the data are clustered into training data, which includes 25 infection cases, 30 metastases cases, and 50 normal cases. While the rest are testing data which includes 25 infection cases, 25 metastases cases, and 25 normal cases. The $\mathrm{Hu}$ moment invariants ( $\phi_{1}$ until $\left.\phi_{7}\right)$ of each data images are calculated to become the input of neural network. The backpropagation neural network algorithm that used in this research are (Rulaningtyas, et al, 2011) :

1. Step 0: Initialize weight and bias (random)

2. Step 1: If stopping condition is still not met, run step 2-9

3. Step 2: For each training data, do steps 3-8

4. Step 3: Each input unit $(x i, i=1, \ldots, n)$ receives the input signal xi and spreads the signal to all units in the hidden layer

5. Step 4: Each hidden unit $(\mathrm{zi}, \mathrm{j}=1, \ldots, \mathrm{p})$ will add the input signals that have weighted, including the bias.

$$
z_{-} i n_{j}=v 0_{j}+\sum_{i=1}^{n} x_{i} v_{i j}
$$

and use the activation function of the hidden unit,

$$
z_{-} i n_{j}=v 0_{j}+\sum_{i=1}^{n} x_{i} v_{i j}
$$

then send this output signal to all units

6. Step 5: Each unit of output ( $\mathrm{yk}, \mathrm{k}=1, \ldots, \mathrm{m})$ will add the input signals that have weighted, including the bias,

$$
y_{-} i n_{k}=w 0_{k}+\sum_{j=1}^{p} z_{j} w_{j} k
$$

and use the activation function of the output unit concerned,

$$
y_{k}=f\left(y_{i n_{k}}\right)
$$

7. Step 6: Each output unit $(\mathrm{yk}, \mathrm{k}=1, \ldots, \mathrm{m})$ accepts a target (expected output) that will be compared to the output produced.

$$
\delta_{k}=\left(t_{k}-y_{k}\right) f^{\prime}\left(y_{i n_{k}}\right)
$$

This $\delta \mathrm{k}$ factor is used to calculate error correction $\left(\Delta \mathrm{w}_{\mathrm{jk}}\right)$ which will later be used to update time, where

$$
\Delta w_{j k}=a \delta_{k} z_{j}
$$


In addition, the bias correction $\Delta \mathrm{w}_{0 \mathrm{k}}$ is calculated which will be used to update $\Delta \mathrm{w}_{0 \mathrm{k}}$, where

$$
\Delta w_{j k}=a \delta_{k}
$$

This $\delta \mathrm{k}$ factor is sending to the layer in front of it.

8. Step 7: Each hidden unit $(\mathrm{zj}, \mathrm{j}=1, \ldots, \mathrm{p})$ sums up the delta input (which is sent from the layer in step 6) which is already weighted.

$$
\delta_{-} i n_{k}=\sum_{k=1}^{m} \delta_{k} w_{j k}
$$

Then the results are multiplied by the derivative of the activation function used by the network to generate an error correction factor $\delta \mathrm{j}$, where:

$$
\delta_{j}=\delta_{-} i n_{k} f^{\prime}\left(z_{i n_{j}}\right)
$$

This factor $\delta_{\mathrm{j}}$ is used to calculate error correction $\left(\Delta \mathrm{v}_{\mathrm{ij}}\right)$ that will be used to update the $\mathrm{v}_{\mathrm{ij}}$, where:

$$
\Delta v_{i j}=a \delta_{j} x_{i}
$$

$\Delta \mathrm{v} 0 \mathrm{j}$ bias correction is also calculated which will be used to update $\mathrm{v} 0 \mathrm{j}$, where:

$$
\Delta v_{0 j}=a \delta_{j}
$$

9. Step 8: Each unit of output ( $\mathrm{yk}, \mathrm{k}=1, \ldots, \mathrm{m})$ will update the bias and weight in each hidden unit

$$
w_{j k}(\text { baru })=w_{j k}(\operatorname{lama})+\Delta w_{j k}
$$

Likewise for each hidden unit will update the bias and their weight on each input unit.

$$
v_{i j}(\text { baru })=v_{i j}(\text { lama })+\Delta v_{i j}
$$

10. Step 9: Check the stopping condition

\subsection{Result and Discussion}

The identification software for brain infection and metastasis brain tumor developed in this research is shown in the Figure 5.

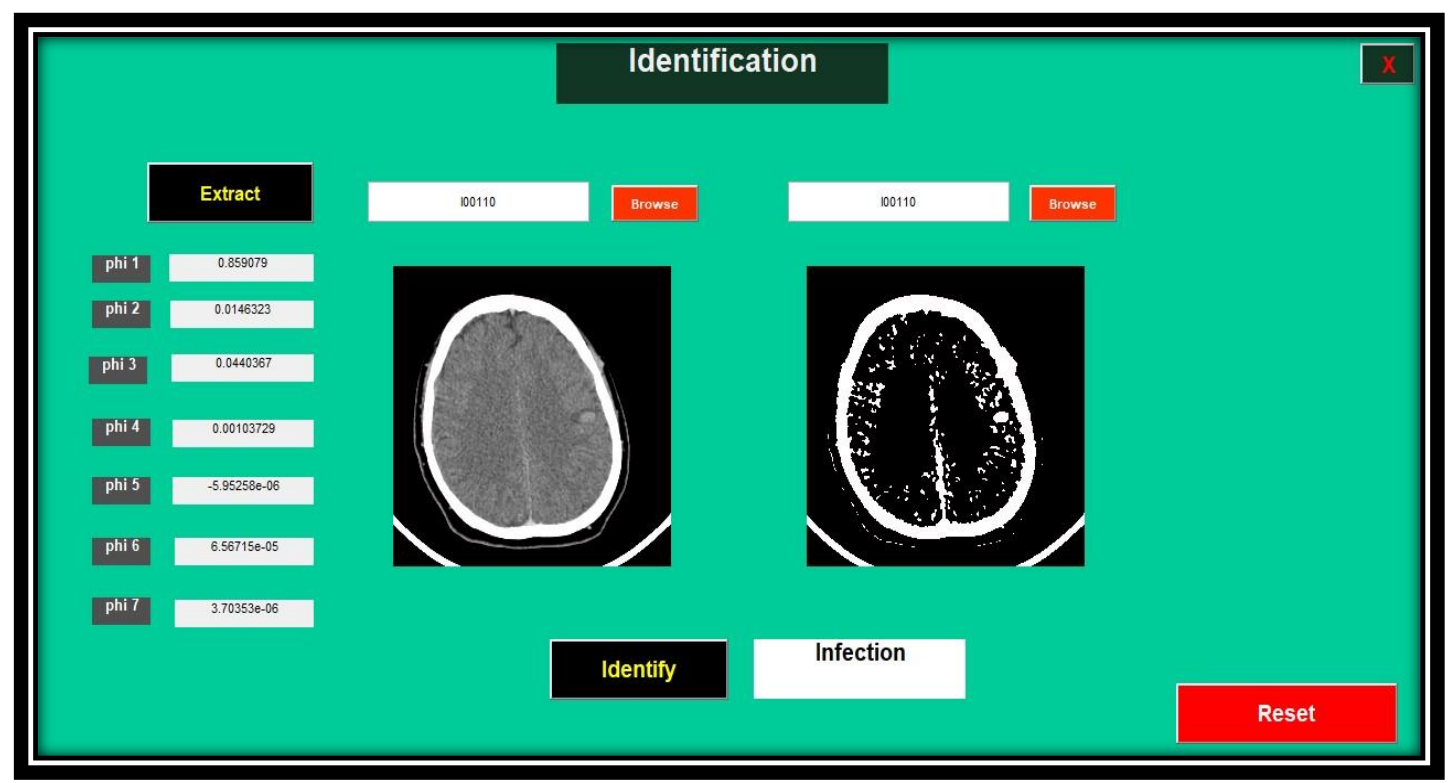

Figure 5. The Visualization of the Resulted Software 
The result of feature extraction using Hu moment invariants method is shown in Figure 6. From Figure 6, the values of the $\mathrm{Hu}$ moment invariants could be separated into three threshold values, they are 1,0 , and 0.5 . It showed that all The $\mathrm{Hu}$ moment invariant features have significant and meaningful values to distinguish the brain disease. From the BPNN training process gives the threshold values 1 for brain infection, 0.5 for metastasis brain tumor, and 0 for normal brain. The $\mathrm{Hu}$ moment invariants features will be classified using backpropagation neural network with sigmoid activated function that the target value is determined by range number 0 until 1 .
The initial weight values of BPNN is random between -1 until 1 . The parameters that are chosen to be optimized in BPNN architecture are the number of hidden nodes, the value of learning rate, and the number of maximum epochs. From the experiment shows that the BPNN architecture with 10 nodes hidden, learning rate 0.5 , and maximum epochs 10000 are giving the best performance with highest accuracy (in Figure 7). From MSE (Mean Square Error) graphic in Figure 8, It shows that the error gives the decrease trend until steady state condition reached in the epoch 1000 with MSE 0.0242. For calculating the MSE values, this research used Eq.24.

$$
M S E=\frac{1}{b} \sum_{a=1}^{b}\left(y_{d N N}-y_{o N N}\right)^{2}
$$

With $b$ : the number of data, $y_{d N N}=$ the desired neural network output, $y_{o N N}=$ the neural network output.

\section{The Values of Hu Moment Moment Invariant}

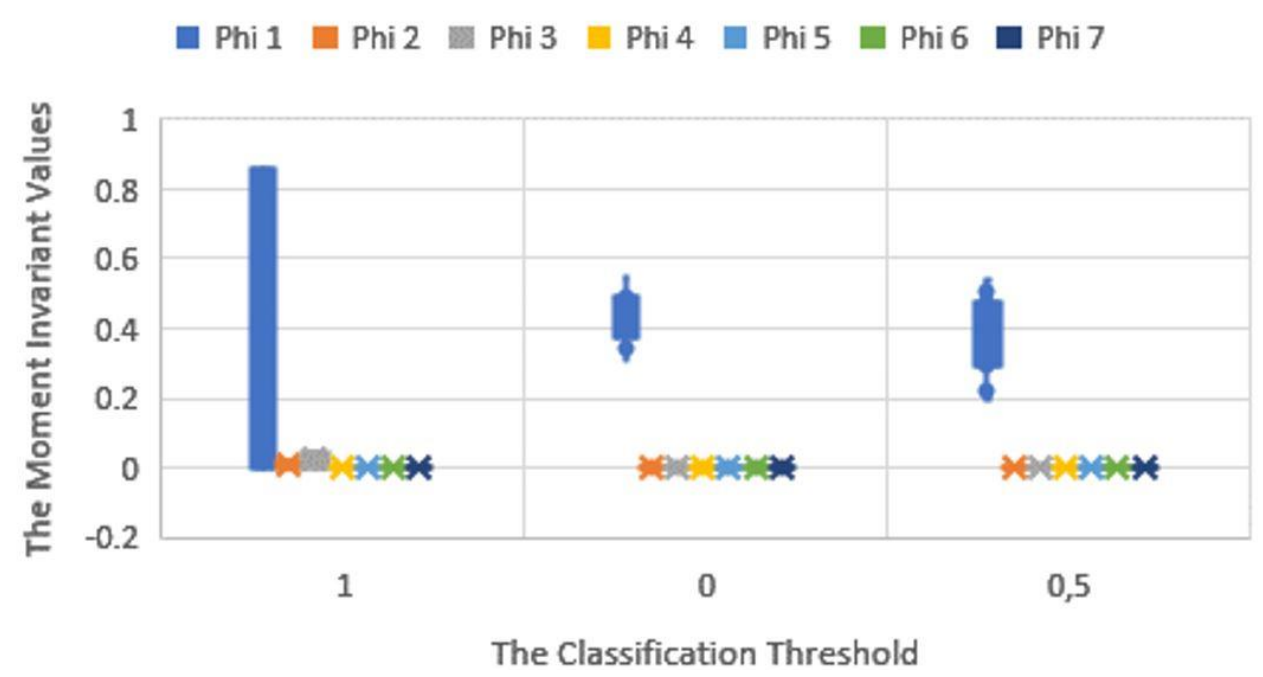

Figure 6. The Hu moment invariants Result 


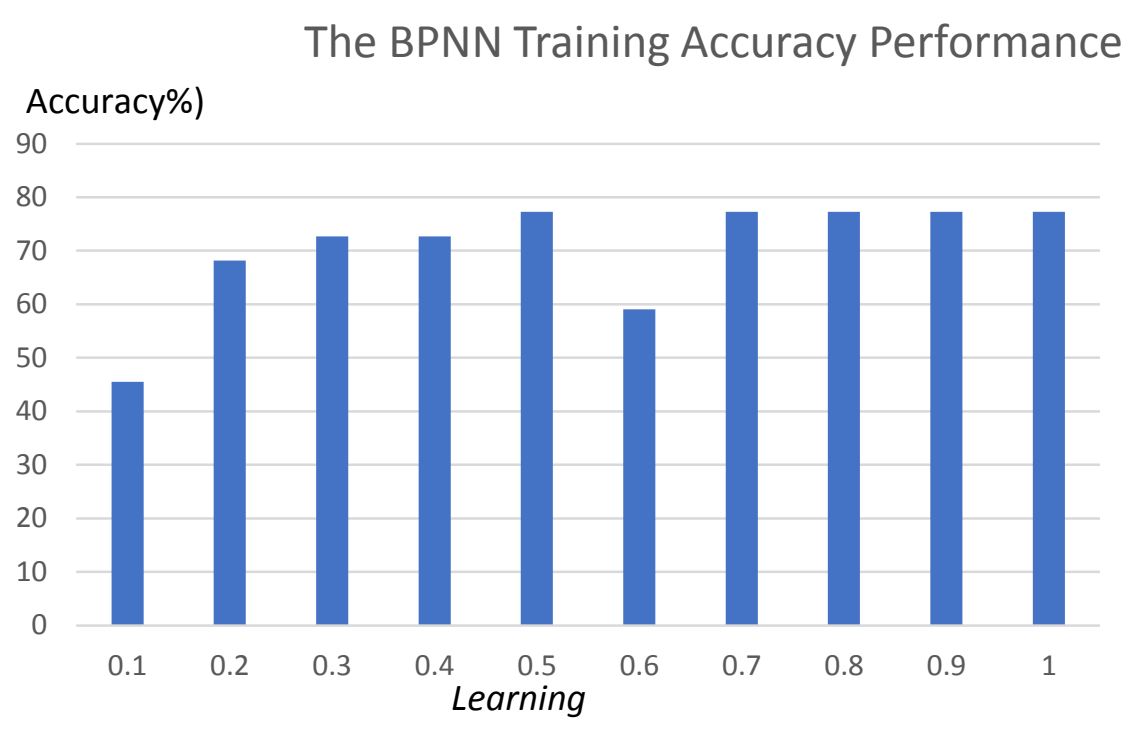

Figure 7. The Comparison of Accuracy Values with the Learning Rate Variation

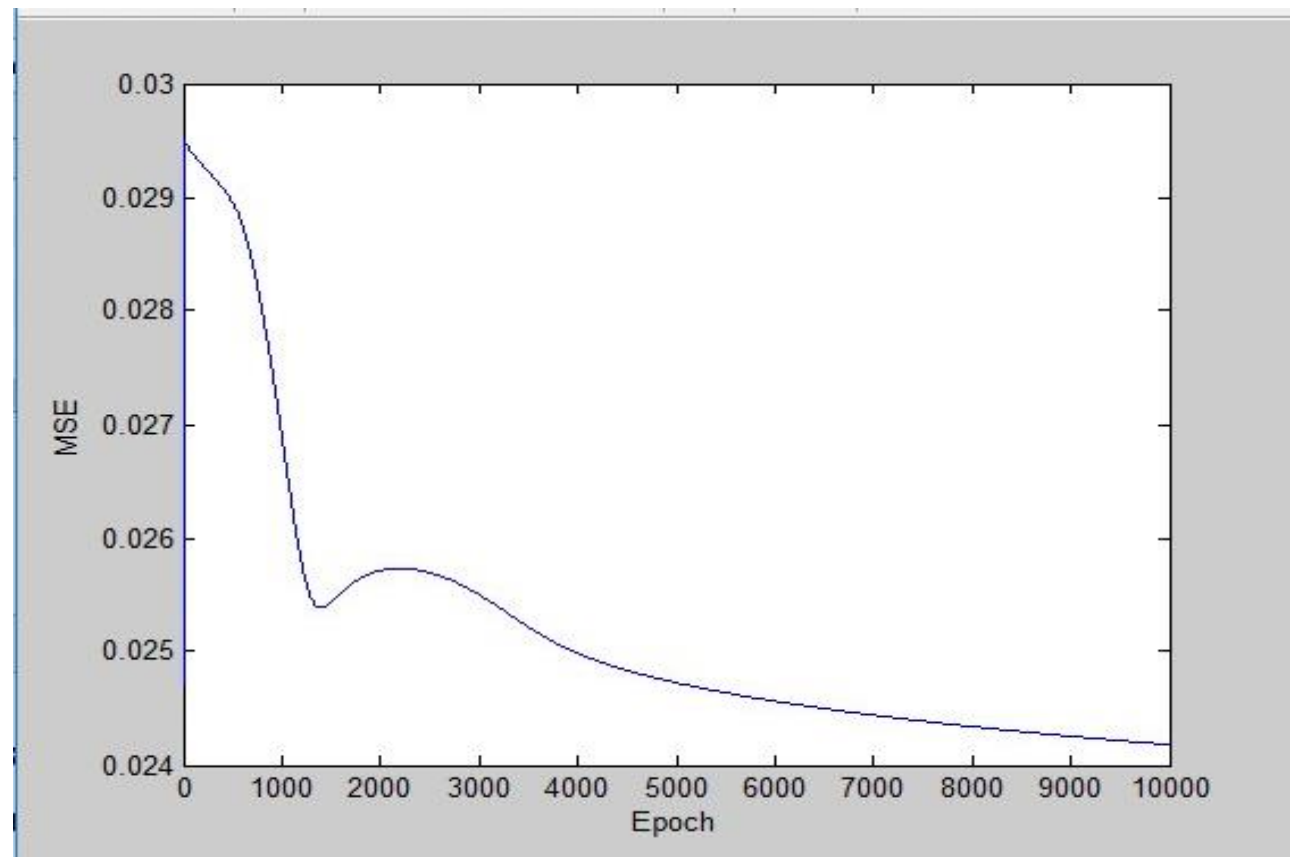

Figure 8. MSE Values from BPNN Training

The measured parameter for succeed classification process is derived by calculation of the accuracy, sensitivity, and specificity values when all the data training and testing compared with the golden standard from the doctors and clinicians. The summary of the research result is represented in Table 1. 


$$
\begin{gathered}
\text { Accuracy }=\frac{T_{P}+T_{N}}{P+N} \times 100 \% \\
P=T_{P}+F_{N} \text { dan } N=F_{P}+T_{N} \\
\text { Sensitivity }=\frac{T_{P}}{T_{P}+F_{N}} \times 100 \% \\
\text { Specificity }=\frac{T_{N}}{F_{P}+T_{N}} \times 100 \%
\end{gathered}
$$

Where :

$$
\begin{aligned}
& T_{P}=\text { True positive } \\
& T_{N}=\text { True negative } \\
& F_{P}=\text { False positive } \\
& F_{N}=\text { False negative }
\end{aligned}
$$

The accuracy represents that the resulted software could classify the all features between normal, brain infection, and metastasis brain tumor cases. The sensitivity represents that the resulted software could classify the features between the normal brain and abnormal brain. The specificity represents that the resulted software could classify the ring features between the brain infection and metastasis brain tumor properly.

Table 1. The Summary of Research Result

\begin{tabular}{cc}
\hline The Parameters & The Values \\
\hline Mean Square Error BPNN & 0.0242 \\
Accuracy & $88.9 \%$ \\
Sensitivity & $86 \%$ \\
Specificity & $100 \%$ \\
\hline
\end{tabular}

\section{CONCLUSION}

Hu moment invariants can identify the pattern of ring enhancing lesion in brain infection and metastasis brain tumor with good accuracy. Hu moment invariants could not be influenced by the position, scale, and rotation position of the brain images in CT Scan. It extracts suitable features for classification as seen in this research the BPNN could distinguish the brain abnormalities, brain infection and metastasis brain tumor with good result in accuracy, sensitivity, and specificity.
To improve the performance of identifying the ring enhancing lesion, this research still needs more development in pattern recognition method to measure the irregularities in the ring boundary shapes. We can try to use unsupervised machine learning method to overcome this problem. The machine learning will adjust their self adaptively to suit the shape of boundary objects that will be identified. 


\section{ACKNOWLEDGMENT}

We would like to thank to Hajj Hospital Surabaya for providing the CT Scan data and to all the doctors and clinicians who cooperated and supported this research.

\section{REFERENCES}

Claussen C, R. Fahlbusch, R. Felix, T, Grumme . 1. Heinzerling 1.R. Iglesias. (1982) Computed and Tomography. Springer-Verlag Berlin Heidelberg.Dewi, M., Loho, E., \& Tubagus, V. N. (2015). Gambaran CTscan neoplasma intrakranial di Bagian / SMF Radiologi FK Unsrat RSUP Prof . Dr . R . D . Kandou Manado, 4(September 2015).

Huang, Z., \& Leng, J. (2010). Analysis of $\mathrm{Hu}$ 's Moment Invariants on Image Scaling and Rotation. 2nd International Conference on Computer Engineering and Technology (ICCET), Volume 7, 476-480.

https://doi.org/10.1109/ICCET.2010.5 485542

Rulaningtyas, R, Suksmono, B, Mengko, T, L, R, Putri, S. (2011). Automatic Classification of Tuberculosis
Bacteria Using Neural Network. IEEE Xplore, page 1-4.

Sun, W., Xu, Y. (2016). Using a Back Propagation Neural Network Based On Improved Particle Swarm Optimization to Study the Influential Factors of Carbon Dioxide Emissions in Hebei Province, China. Journal of Cleaner Production 112(2016), 1282-1291. Elsevier. Zhang, Y., Yang, J., Wang, S., Dong, Z., \& Phillips, P. (2016). Pathological Brain Detection in MRI Scanning via $\mathrm{Hu}$ Moment Invariants and Machine Learning. Journal of Experimental \& Theoritical Artificial Intelligence, 29(2), 299-312. doi:10.1080/0952813x.2015.1132274.

Zhang, Y., Wang, S., Sun, P., Phillips, P. (2015). Pathological Brain Detection Based on Wavelet Entropy and $\mathrm{Hu}$ moment invariants. Bio-Medical Materials and Engineering. Vol.26, Page S1283-S1290. IOP Press.

Zunic, J., Hirota, K., Rosin, P.L. (2010). A $\mathrm{Hu}$ moment invariants as A Shape Circularity Measure. Pattern Recognition. Volume 43, Issue 1, Pages 47-57. Elsevier. 